\title{
The Relationship between \\ Electromyographically Documented Peripheral Neuropathy and Falls
}

\author{
James K. Richardson, $M D,{ }^{*}+$ Christopher Ching, $M D$, and Edward A. Hurvitz, MD*†
}

\begin{abstract}
Objective: To determine if the presence of an electromyographically demonstrated peripheral polyneuropathy involving the lower extremities is associated with falls.

Design: Case control study.

Setting: A University-based referral center.

Patients: Twenty-five patients with an axonal peripheral polyneuropathy affecting the lower extremities, demonstrated by electromyography more than 8 and less than 16 months before, and 25 age- and sex-matched controls who had normal electromyographic studies of the lower extremities during the same time period, were identified from a computer record of all electromyography results during the year prior to the study, using diagnostic codes and demographic data. Twenty-eight pairs were identified, 25 of whom completed the study.
\end{abstract}

Main Outcome Measures: Number of falls and resuitant injuries during the year before the interview, and number of previously identified risk factors for falling, based on interview.

Results: Peripheral neuropathy was found to be significantly associated with falling $(14 / 25,56 \%$ vs $2 / 25,8 \%$ - odds ratio $23.0,95 \%$ confidence interval $2.5,>100$ ) and repetitive falling $(10 / 25,40 \%$ vs $1 / 25,4 \%$ - odds ratio, $95 \%$ confidence interval $1.4,>100)$. There was a trend toward increased injury requiring medical attention $(5 / 25,20 \%$ vs $0 / 25,0 \%)$, but it did not reach statistical significance. Previously identified risk factors were not significantly more common in the peripheral neuropathy group.

Conclusion: An electromyographically identified peripheral neuropathy is strongly associated with and may be a risk factor for falls. J Am Geriatr Soc 40:1008-1012, 1992

mentioned as a factor contributing to falls. One study found lower extremity "sensory abnormalities" to be a cause of falls in one of the two cohorts studied, ${ }^{5}$ and another noted that decreased position sense at the toe with continuous benzodiazepine use increased fall risk. ${ }^{12}$ Peripheral neuropathy in patients with $\mathrm{Alz}$ heimer's disease has been identified as a cause of falls, ${ }^{13}$ and Sabin discussed neuropathy as one of several possible models to explain falls in the elderly. ${ }^{14}$ Others have failed to identify neuropathy as a cause of falls. Wolfson et al noted that clinical signs of peripheral neuropathy were common and equally distributed between groups of elderly fallers and nonfallers, ${ }^{15}$ while another study found no relationship between abnormal position/vibratory sense in the feet and falls. ${ }^{16}$ A large recent case control study failed to identify neuropathy as a cause of hip fractures in elderly women. ${ }^{17}$ None of these studies focused on peripheral neuropathy as a primary risk factor for falls or detected the presence of neuropathy electromyographically. The present study was designed to determine if electromyographically documented peripheral neuropathy is associated with a history of falls and with risk factors for falls.

\section{METHODS}

The Review Board at this institution approved the study. The subjects and control patients were selected consecutively from a computer listing of all patients who had an electromyographic study of the lower extremities performed during the 8-16 months prior to interview. Diagnostic codes were used to identify cases of neuropathy through the EMGPRO ${ }^{18}$ software system, and the studies were reviewed by an author (JR) 
to determine if they matched criteria for the diagnosis. The criteria for inclusion were:

a) Conclusive electromyographic evidence of a primarily axonal peripheral neuropathy in the lower extremities, including:

(1) Sural response-absent or decreased in amplitude $(<6 \mu \mathrm{V})$ with a normal or minimally prolonged distal latency $(<5.0 \mathrm{~ms}$ stimulating 14 centimeters from recording site).

(2) Peroneal and/or tibial motor responses-absent or decreased in amplitude $(<2,3 \mathrm{mV}$ respectively) with normal distal latency ( $<6.2 \mathrm{~ms}$ stimulating 9 and 8 centimeters from recording sites).

(3) No other electrodiagnostic abnormalities.

b) Willingness to be interviewed by telephone.

c) Ability to speak and understand English and cognitive ability to complete the interview.

d) Ability to walk.

The control patients were identified from the same computer list by diagnostic code ("normal") and then age- and sex-matched with the subjects. If a perfect age match could not be identified, a control who was a few years older was used.

An author (CC) and an assistant who were blinded to the electromyographic results interviewed the control patients and subjects by telephone. They used a standardized introduction to obtain permission for the interview and to explain the study. The data about falls and known risk factors for falls were then collected. A fall was defined as an unintentional change in body posture that resulted in the person being on a lower level. In order to be included, a fall needed to have occurred during the previous year, and the subject or control needed to be able to completely describe the circumstances surrounding the fall. If a subject was not able to describe the details of a fall, including body posture, the location or environment of the fall, and any accompanying symptomatology, then the event was not recorded. The number of falls, the resultant injuries, and the type of activity when falling were recorded. Then information regarding conditions that are known to increase the risk of falling was obtained. The interviewers specifically asked about the use of assistive devices, depression, stroke, Parkinson's disease, weakness, postural light headedness, lower extremity weakness, deformities, arthritis or surgery, impairment of vision or hearing, cardiovascular disease including cardiac dysrhythmia, and use of medications or alcohol. The medical chart was reviewed for clarification when subjects or controls were uncertain regarding diagnoses or medications.

The odds of falling within the year prior to the interview for patients with peripheral neuropathy was compared to the odds for those patients without peripheral neuropathy. The data were analyzed using matched data techniques as described by Kelsey et al, ${ }^{19}$ with the confidence limits around the point estimate of the odds ratio determined using the method of Miettinen. ${ }^{20}$ Due to the small number of pairs, a correction factor (.5) was used in each calculation. The small numbers also led to a wide confidence interval, and only the lower limit is reported with precision. In this setting, where the outcome in question is greater than $50 \%$ in one group, the odds ratio will greatly overstate the relative risk, but still provide information about significance. The odds ratio for near-falls (stumbles) was based only on those pairs where neither of the members fell completely (11 pairs, five near-falls in the peripheral neuropathy group, none in the control group).

The two groups were not matched for prevalence of risk factors or reason for referral, so these factors were examined for significant differences between the two groups. Chi square was used for reason for referral, overall risks and multiple risks, while Fischer's exact test was used for the other risks (Table 2). Systat ${ }^{21}$ software was used for this part of the analysis.

\section{RESULTS}

Fifty-six patients were entered into the study from computer records. Two intended subjects and two intended control patients refused the interview. An intended subject was cognitively impaired and could not effectively communicate, and an intended control used a wheelchair for mobility. Fifty patients ( 25 age- and sex-matched pairs) completed the interviews. There were 32 males and 18 females in the group, with an average age of 61.0 years (range $25-80$ years). The neuropathy group had an average age of 60.0 years (range 25-79, median 62 years) and the control group had an average age of 62.1 (range 27-80, median 66 years). The reasons for referral for EMG were surprisingly similar between the two groups (Table 1). Clinical suspicion of neuropathy or referral for weakness was only slightly greater in the neuropathy group than the control group, and this difference was not statistically significant. Notably, none of the patients in either group was referred for evaluation of falling. As would be expected, the amplitudes of the nerve responses were markedly decreased in the neuropathy group when compared with the controls (Table 2).

Patients with peripheral polyneuropathy had significantly more falls during the year prior to the interview $(14 / 25,56 \%$ vs $2 / 25,8 \%$; Table 3$)$. Repetitive falling was also significantly increased in the neuropathy group $(10 / 25,40 \%$ vs $1 / 25,4 \%$; Table 3$)$. There was a trend toward an increase in the number of subjects

\section{TABLE 1. REASON(S) GIVEN FOR EMG TESTING} BY REFERRING PHYSICIANS*

\begin{tabular}{lcc}
\hline $\begin{array}{c}\text { Clinical Suspicion } \\
\text { or Diagnosis }\end{array}$ & $\begin{array}{c}\text { No. of } \\
\text { Control } \\
\text { Subjects }\end{array}$ & $\begin{array}{c}\text { No. of } \\
\text { Neuropathy } \\
\text { Subjects }\end{array}$ \\
\hline $\begin{array}{l}\text { Neuropathy } \\
\text { Lower extremity radicu- }\end{array}$ & 10 & 13 \\
$\begin{array}{l}\text { lopathy } \\
\text { Weakness }\end{array}$ & 12 & 4 \\
Pain & 4 & 4 \\
Numbness & 1 & 1 \\
Upper extremity symp- & 1 & 3 \\
toms & 0 & 2 \\
No reason or diagnosis re- & & 2 \\
corded & & \\
\hline
\end{tabular}

* The reasons for testing for each group total greater than 25 because referring physicians at times gave more than one reason. 
TABLE 2. AVERAGE AMPLITUDES AND LATENCIES OF NERVE CONDUCTION STUDIES FOR NEUROPATHY AND CONTROL GROUPS

\begin{tabular}{|c|c|c|c|c|c|c|}
\hline & \multicolumn{2}{|c|}{ Sural } & \multicolumn{2}{|c|}{ Peroneal } & \multicolumn{2}{|c|}{ Tibial } \\
\hline & $\underset{(\mu \mathrm{V})}{\text { Amplitude }}$ & $\begin{array}{l}\text { Latency } \\
\text { (ms) }\end{array}$ & $\begin{array}{c}\text { Amplitude } \\
\text { (mV) }\end{array}$ & $\begin{array}{c}\text { Latency } \\
\text { (ms) }\end{array}$ & $\begin{array}{c}\text { Amplitude } \\
\text { (mV) }\end{array}$ & $\begin{array}{l}\text { Latency } \\
\text { (ms) }\end{array}$ \\
\hline $\begin{array}{l}\text { Neuropathy group } \\
\text { average }\end{array}$ & 1.2 & 4.4 & 1.2 & 5.5 & 2.4 & 5.5 \\
\hline Control group average & 11.2 & 3.8 & 6.6 & 4.9 & 12.3 & 4.7 \\
\hline
\end{tabular}

TABLE 3. FALLS, REPETITIVE FALLS, NEAR FALLS, AND INJURIES (25 PATIENTS IN EACH GROUP)

\begin{tabular}{lcccc}
\hline & $\begin{array}{c}\text { Neuropathy } \\
\text { Group }\end{array}$ & $\begin{array}{c}\text { Control } \\
\text { Group }\end{array}$ & $\begin{array}{c}\text { Odds } \\
\text { Ratio }\end{array}$ & $\begin{array}{c}\text { Confidence } \\
\text { Intervals }\end{array}$ \\
\hline Falls & 14 & 2 & 23.0 & $2.5,>100$ \\
Repetitive falls & 10 & 1 & 6.3 & $1.4,>100$ \\
Injuries & 5 & 0 & 9.0 & $0.8,>100$ \\
Near-falls & 5 & 1 & 9.0 & $0.8,>100^{*}$ \\
\hline
\end{tabular}

* Calculated only with non-falling pairs.

who experienced stumbling or near-falls and injuries, but neither of these trends was statistically significant. The injuries of the five patients who fell included one hip fracture, three lacerations requiring sutures, and one chronic sacral pain syndrome. The two controls who fell were not injured.

Prevalence of risk factors for falling, including incidence of patients with multiple risk factors, was similar in the two groups (Table 4). Of these risk factors, the most marked difference between the two groups was found in the use of medications associated with falls. Ten subjects with neuropathy used 14 of such medications, while seven controls used eight of these drugs. Seven of the 10 subjects with neuropathy and on a high risk drug had fallen, including all four on both a diuretic and a tricyclic antidepressant. None of the seven controls on medications associated with falling had done so.

There were nine diabetics in the neuropathy group, six of whom fell, and none in the control group. Because of the high incidence of autonomic dysfunction in diabetics, it was hypothesized that postural hypotension was the true cause of these subjects' falls. If this were true, peripheral neuropathy would be acting as a marker for postural hypotension rather than as an independent risk factor. However, analysis of the data with these six pairs removed revealed that peripheral neuropathy remained a significant risk factor for falls (odds ratio $11.0,95 \%$ CI 1.02, > 100).

The circumstances of the falls were variable. One of the controls had a history of cardiovascular disease and fell with an episode of neck extension. The other control stated that she had "chronic fatigue syndrome" and at times "flopped" to the floor because of weakness while doing housework. In the neuropathy group, 10 could identify no environmental reason for their falls; however, the subjects all maintained continuous memory throughout their falls and denied syncopal symptoms. Four others identified obstacles or activities (climbing a small hill, missing a step on a ladder,
TABLE 4. RISK FACTORS FOR FALLS*

\begin{tabular}{lcc}
\hline & $\begin{array}{c}\text { Neuropathy } \\
\text { Group }\end{array}$ & $\begin{array}{c}\text { Control } \\
\text { Group }\end{array}$ \\
\hline Any risk & 17 & 13 \\
Multiple risk & 7 & 6 \\
Drug, any & 10 & 7 \\
CNS drug & 5 & 4 \\
Diuretics & 9 & 4 \\
Arthritis & 4 & 4 \\
Cardiovascular disease & 3 & 7 \\
Assistive device & 7 & 4 \\
Depression & 0 & 1 \\
Postural light headedness & 3 & 0 \\
Seizure disorder & 1 & 0 \\
\hline
\end{tabular}

* Risk factors are based on previously referenced studies. No significant difference between the groups for any factor. Please see text for details of analysis.

moving from sit to stand, and ground irregularities) as the source of their falls.

\section{DISCUSSION}

This study suggests that peripheral neuropathy is associated with falls. The neuropathy group had a significantly greater number of one-time fallers and repetitive fallers. The falls were not trivial in the neuropathy subjects, causing serious injury in five of the 14 subjects who fell. Neither of the two controls who fell were injured. In addition, it is possible that neuropathy may be an independent risk factor for falls since the frequency of concurrent, known risk factors for falls was not significantly different between the two groups.

A limitation of this study is its retrospective design and reliance upon subject memory for data. To lessen the chance for error, subjects were required to completely describe the circumstances of the fall if it was to be included in the study. No falling event had to be excluded on this basis; possibly because of the psychologic trauma known to accompany falls, ${ }^{22}$ all falls were recounted in detail. In addition, falls were included only if they had occurred within the last year. It was assumed that memories would be less accurate if greater than a 1-year history was requested, and the certainty of the presence of neuropathy would lessen if history was requested for more than 4 months prior to the EMG.

Another possible limitation to the study is the reliance upon subject memory and self perception for the recollection and identification of other risk factors known to cause falls. Subjects very likely made errors, 
but there is no reason to suspect that either the control or neuropathy subjects as a group under- or overreported these risk factors, and, therefore, it seems unlikely that systematic error was introduced. It is difficult to determine if bias might have been introduced if subjects knew the results of their EMG during the study period. Subjects with neuropathy may have then been more aware of any perturbations in their mobility as a result of their knowledge of the EMG. On the other hand, knowledge of the presence of neuropathy may have inspired the subjects to be more cautious and decrease their fall risk. Therefore, it seems unlikely that any unidirectional bias was introduced by the subjects knowing their EMG results.

Some known risk factors for falling cannot be identified by phone or chart review. Physical findings such as pronator drift, muscle weakness, extrapyramidal signs, and postural hypotension would be undetected by interview. With the exception of postural hypotension, which could occur more frequently in the neuropathy group with its diabetic subjects, there is no reason to suspect that these findings would be unequally distributed between the two groups. However, as noted above, if all six of the nine diabetics who fell are assumed to have fallen from postural hypotension and eliminated from the study, a barely statistically significant association between peripheral neuropathy and falls remains, suggesting that the neuropathy effect may be independent of any associated autonomic dysfunction.

With the exception of ruling out radiculopathy, which was a significantly more common reason for referral for EMG in the control group, the reasons for referral were similar in the two groups. Presumably, the reason for referral grossly reflects patient symptomatology, physician suspicion, or both. This suggests that the two groups were relatively homogeneous in terms of lower extremity symptomatology and clinical presentation. This homogeneity lends strength to the EMG's apparent ability to discriminate among diagnoses and identify those patients at high risk for falling.

Little has been written about the possible relationship between peripheral neuropathy and falls. One study found a higher frequency of abnormal electromyographic sural nerve and $\mathrm{f}$-responses in a group of elderly fallers compared with elderly non-fallers. ${ }^{23}$ That study differed from ours in that fallers were identified prior to the EMG results. Sabin ${ }^{14}$ suggested neuropathy as a possible mechanism for falls in the elderly. He emphasized not only the sensory and proprioceptive loss in patients with neuropathy, but also the resultant muscle imbalance that might occur at the ankle. In peripheral neuropathy the anterior tibialis muscle may be relatively weaker than the calf because of the greater length of the peroneal nerve compared with the tibial. Whipple et $\mathrm{al}^{\mathbf{4}}$ provided evidence which indirectly supports Sabin's hypothesis in a study which measured the strengths of knee flexors/extensors and ankle plantar flexors/dorsiflexors in a group of elderly, one-half of whom had a history of falls. Fallers were found to be generally weaker than the non-fallers in all four muscle groups, but disproportionately weaker in the ankle dorsiflexors. This would be predicted if the falling group included a substantial number of subjects with peripheral neuropathy. Weak dorsiflexors could obviously contribute to stubbing of the forefoot on environmental barriers, since the weakened leg does not functionally shorten via dorsiflexion in the swing phase of gait. In addition, the importance of dorsiflexion as the event which initiates reestablishment of balance after application of a posterior displacement force has been emphasized. ${ }^{15}$

The presence of peripheral neuropathy may be a common denominator for other abnormalities that have been noted in fallers as well. Foot abnormalities have been described as occurring with increased frequency in fallers. ${ }^{4}$ Peripheral neuropathy leads to atrophy of the foot intrinsic muscles which in turn leads to hammer toes, metatarsalgia, and loss of normal arch. Increased sway has been noted in patients who fall. ${ }^{25}$ It is reasonable to suspect that patients with peripheral neuropathy, with the accompanying decrease in foot pressure perception and joint position sense, would demonstrate increased sway. Finally, multiple stumbles have been associated with falls. ${ }^{7}$ Five of the neuropathy subjects gave a history of repetitive stumbles without falling, suggesting that neuropathy may underlie this impairment as well.

This study indicates that, because of the relationship between neuropathy and falls, close attention should be paid to the lower extremity neurological examination in patients who have fallen or are at risk. However, as mentioned above, other studies have not found the relationship. This apparent conflict with the present study may be explained by the fact that electromyography, which was used in this study, is superior to clinical examination in detecting peripheral neuropathy. Therefore, if these results are confirmed in prospective studies that include direct measurement of fall risk factors, then it may be useful to perform electromyographic studies on patients who have fallen without apparent cause, or those at risk for falls from other causes. If neuropathy is found, medications such as diuretics and long-acting sedatives should be avoided to prevent compounding fall-risk factors. In addition, patients with neuropathy should be counseled to use a cane, especially in areas of poor lighting or unfamiliar terrain, and to purchase wide-soled shoes to increase the base of support.

\section{ACKNOWLEDGMENT}

The first author would like to thank his father, Joseph H. Richardson, MD, for his review of this manuscript.

\section{REFERENCES}

1. Prudham D, Evans JG. Factors associated with falls in the elderly: A community study. Age Ageing 1981;10:141-146.

2. Gryfe CI, Amies A, Ashley Mj. A longitudinal study of falls in an elderly population: I. Incidence and morbidity. Age Ageing 1977;6:201-210.

3. Tinetti ME. Factors associated with serious injury during falls by ambulatory nursing home residents. J Am Geriatr Soc 1987;35:644-648.

4. Tinetti ME, Speechley M, Ginter SF. Risk factors for falls among elderly persons living in the community. N Engl J Med 1988;319:1701-1707.

5. Robbins AS, Rubenstein LZ, Josephson KR et al. Predictors of falls among elderly people. Arch Intern Med 1989;149:1628-1633.

6. Campbell AJ, Reinken J, Allan BC et al. Falls in old age: A study of 
frequency and related clinical factors. Age Ageing 1981;10:264-270.

7. Teno J, Kiel DP, Mor V. Multiple stumbles: A risk factor for falls in community-dwelling elderly. J Am Geriatr Soc 1990;38:1321-1325.

8. Gehisen GM, Whaley MH. Falls in the elderly: Part II, balance, strength, and flexibility. Arch Phys Med Rehabil 1990;71:739-741.

9. Gerson LW, Jarjoura D, McCord G. Risk of imbalance in elderly people with impaired hearing or vision. Age Ageing 1989;18:31-34.

10. Gordon M, Huang $M$, Gryfe $\mathrm{Cl}$. An evaluation of falls, syncope, and dizziness by prolonged ambulatory cardiographic monitoring in a geriatric institutional setting. J Am Geriatr Soc 1982;30:6-12.

11. Sobel KG, McCart GM. Drug use and accidental falls in an intermediate care facility. Drug Intell Clin Pharm 1983;17:539-542.

12. Sorock GS, Shimkin EE. Benzodiazepine sedatives and the risk of falling in a community-dwelling elderly cohort. Arch Intern Med 1988;148: 2441-2444.

13. Buchner DM, Larson EB. Falls and fractures in patients with Alzheimertype dementia. JAMA 1987;257:1492-1495.

14. Sabin TD. Biologic aspects of falls and mobility limitations in the elderly. J Am Geriatr Soc 1982;30:51-58.

15. Wolfson LI, Whipple RH, Amerman PM et al. Stressing the postural response-a quantitative method for testing balance. J Am Geriatr Soc
1986;34:845-850.

16. Nevitt MC, Cummings SR, Kidd $S$ et al. Risk factors for recurrent nonsyncopal falls. JAMA 1989;261:2663-2668.

17. Grisso JA, Kelsey JL, Strom BL et al. Risk factors for falls as a cause of hip fracture in women. N Engl J Med 1991;324:1326-1331.

18. EMGPRO, University of Michigan Software, $475 \mathrm{E}$. Jefferson Rm. 23554, Ann Arbor, MI 48109-1092.

19. Kelsey JL, Thompson WD, Evans AS. Methods in Observational Epidemiology. New York: Oxford University Press, 1986, pp 178-182.

20. Mietinnen OS. Estimation of relative risk from individually matched series. Biometrics 1970;26:75-86.

21. Systat Inc., Evanston Illinois, 1990

22. Murphy J, Isaacs B. The post-fall syndrome-A study of 35 elderly patients. Gerontology 1982;28:265-270.

23. Pack DR, Wolfson LI, Amerman PM et al. Peripheral nerve abnormalities and falling in the elderly. Neurology 1985;(suppl)35:79.

24. Whipple RH, Wolfson LI, Amerman PM. The relationship of knee and ankle weakness to falls in nursing home residents: An isokinetic study. J Am Geriatr Soc 1987;35:13-20.

25. Ring C, Nayak USL, Isaacs B. Balance function in elderly people who have and who have not fallen. Arch Phys Med Rehabil 1988;69:261-264. 